\title{
CsrA impacts survival of Yersinia enterocolitica by affecting a myriad of physiological activities
}

\author{
Karen LeGrand ${ }^{1,2^{*}}$, Shane Petersen², Yan Zheng ${ }^{2,3}$, Kang K Liu², Gulustan Ozturk², Jing-Yu Chen ${ }^{2,4}$ \\ and Glenn M Young ${ }^{1,2^{*}}$
}

\begin{abstract}
Background: A previous study identified a Yersinia enterocolitica transposon mutant, GY448, that was unable to export the flagellar type three secretion system (T3SS)-dependent phospholipase, YpIA. This strain was also deficient for motility and unable to form colonies on Lauria-Bertani agar medium. Preliminary analysis suggested it carried a mutation in cSrA. CsrA in Escherichia coli is an RNA-binding protein that is involved in specific post-transcriptional regulation of a myriad of physiological activities. This study investigated how CsrA affects expression of the flagellar regulatory cascade that controls YpIA export and motility. It also explored the effect of csrA mutation on Y. enterocolitica in response to conditions that cue physiological changes important for growth in environments found both in nature and the laboratory.

Results: The precise location of the transposon insertion in GMY448 was mapped within csrA. Genetic complementation restored disruptions in motility and the YplA export phenotype (Yex), which confirmed this mutation disrupted CsrA function. Mutation of CsrA affected expression of yp/A and flagellar genes involved in flagellar T3SS dependent export and motility by altering expression of the master regulators flhDC. Mutation of csrA also resulted in increased sensitivity of $Y$. enterocolitica to various osmolytes, temperatures and antibiotics.

Conclusions: The results of this study reveal unique aspects of how CsrA functions in Y. enterocolitica to control its physiology. This provides perspective on how the Csr system is susceptible to adaptation to particular environments and bacterial lifestyles.
\end{abstract}

Keywords: Yersinia, CsrA, Csr system, Motility, Salt sensitivity, Antibiotic sensitivity, Temperature sensitivity, Psychrotroph, Mutant selection

\section{Background}

Yersinia enterocolitica produces a phospholipase, YplA, that is secreted by the flagellar type 3 secretion system (T3SS) under standard laboratory conditions and can also be exported by the Ysa and Ysc T3SS under different conditions [1,2]. In a previous study, our laboratory developed a transposon mutant library that identified 77 mutants that exhibited a deficiency for YplA export phenotype (Yex) under standard conditions [3]. Three of the mutants carried an insertion of the transposon within the yplA locus. Among the remaining $\mathrm{Yex}^{-}$strains, 74 of these mutants additionally exhibited defects for motility. Subsequent analysis confirmed that the insertion mutation

\footnotetext{
*Correspondence: klegrand@ucdavis.edu; gmyoung@ucdavis.edu 'Microbiology Graduate Group, University of California, Davis, CA, USA Full list of author information is available at the end of the article
}

harbored by 71 of these $\mathrm{Yex}^{-}$strains mapped to genes encoding components of the flagellar T3SS (unpublished data). This result corroborated results from previous studies that established YplA export depends on this T3SS $[2,4]$. Two of the remaining $\mathrm{Yex}^{-}$mutants were affected for production and sensing of the ubiquitous signaling molecule cyclic AMP (cAMP) and the cAMP receptor protein (CRP), which are necessary for normal expression of the flagellar, Ysa and Ysc T3SS [3]. These strains carried mutations mapping to $c y a$ and $c r p$, respectively. The single remaining motility deficient mutant, GY448, was noted to have another striking phenotype; it was not able to grow on Lauria-Bertani (LB) agar medium, but could grow on tryptone yeast extract (TYE) agar medium. Preliminary analysis had suggested GY448 carried a transposon insertion located within a gene homologous to Escherichia coli carbon storage regulator $\mathbf{A}(\operatorname{csr} A)$. 
The $\operatorname{csr} A$ gene, and its ortholog $\operatorname{rsm} A$, has been characterized in $E$. coli and a wide variety of other bacterial species as one that encodes an RNA-binding protein (reviewed in [5]). CsrA is involved in post-transcriptional regulation of many specific genes and consequently coordinates a myriad of physiological activities including metabolism, adaptation to changing environmental conditions and the temporal expression of colonization and virulence factors. Mechanistically, CsrA binds to target mRNAs and, depending on the context of the binding site, is capable of either activating or repressing translation [6]. CsrA function is modulated by additional components of the Csr system. Two highly structured small non-coding regulatory RNA molecules (ncRNA), CsrB and CsrC, are ncRNAs that titrate the amount of CsrA available within the cell by binding to CsrA and sequestering it from target mRNAs [6-8]. Stability of CsrB and CsrC is controlled by CsrD, adding an additional layer of modulation that ultimately affects CsrA availability [9].

\section{Results and discussion}

A) Y. enterocolitica strain GY448 phenotypes can be restored by complementation of $c s r A$ on a low-copy plasmid.

In order to understand the nature of the defect that affected YplA export, motility and growth of GY448 on LB media, the mutation was further characterized. The site of the transposon insertion within the $Y$. enterocolitica genome was precisely mapped. Determination of the DNA sequence of the transposon/chromosome junction revealed the location to be at codon 29 of a predicted orf (Figure 1). The 61 amino acid protein encoded by this orf is $95 \%$ identical to CsrA from $E$. coli, differing only at amino acids 58-60. This orf is also, 94\% identical Salmonella enterica subsp. enterica, serovar Typhimurium and exhibits a high degree of amino acid similarity to various other bacteria. In $E$. coli, CsrA functions as a homodimer in which two

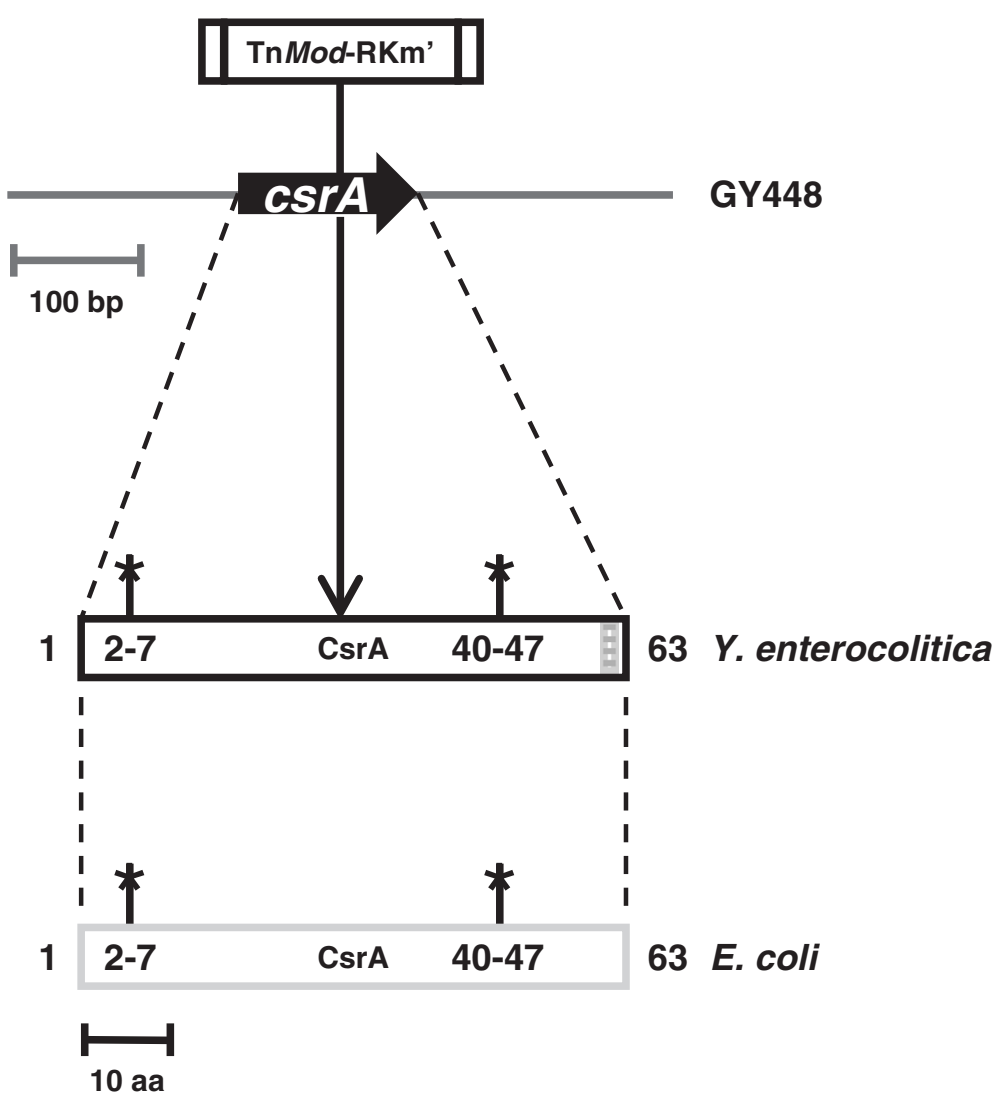

Figure 1 Schematic diagram of csrA region in chromosome of GY448 and CsrA in Y. enterocolitica and E. coli. The location and orientation of the orf is indicated by the thick black arrow. The insertion location of the transposon with the kanamycin resistance cassette (Km) is shown above. The downward arrow from this location indicates the site of the mutation within codon 29 of the protein encoded by the $Y$. enterocolitica orf, which is represented by the black rectangle. The grey rectangle represents CsrA from E. coli. The dashed lines between these three components indicate alignment between the $Y$. enterocolitica orf, the $Y$. enterocolitica protein and the E. coli protein. The stars represent regions essential for dimerization. The numbers represent amino acid position. The small grey shaded region represents non-homology of the $Y$. enterocolitica protein with the E. coli protein. The location of the transposon insertion results in a C-terminal truncation that excludes one of the critical regions essential for dimerization. 
critical regions, amino acids $2-7$ and $40-47$, interact in an antiparallel manner to form a functional domain [10-12]. Thus the transposon insertion was predicted to result in a null mutation since the $\mathrm{C}$-terminal truncation excluded the critical dimerization domain containing residues 40-47.

The prediction that CsrA in GY448 is non-functional was supported by results from genetic complementation analysis. A fragment of DNA with csrA was cloned into the low copy plasmid pTM100 to produce pGY1298. The plasmid was introduced into GY448, resulting in strain GY6535 (csrA/csrA+). As a negative control, the vector, pTM100, was also introduced into GY448, resulting in strain GY6536 (VC). These strains were examined for the ability to export YplA and for motility. The presence of pGY1298, but not pTM100 restored the Yex ${ }^{+}$ phenotype (Figure 2A) and motility (Figure 2B). These results demonstrate that the mutation carried by GY448 disrupted CsrA function.

B) Y. enterocolitica CsrA activates expression of genes encoding the master motility regulators FlhDC.

The Yex ${ }^{-}$phenotype of the csrA mutant of $Y$. enterocolitica may be the result of altered $y p l A$ expression. Therefore, to determine whether CsrA affected yplA expression, a lac reporter system was used in which $l a c Z$ was driven by the promoter region of $y p l A$. Gene expression in wild-type (WT) and the $\operatorname{csr} A$ mutant ( $\operatorname{csr} A$ ) was quantified by measuring $\beta$-galactosidase activity (Figure 3). Expression of yplA was significantly reduced in the $\operatorname{csr} A$ mutant relative to wild-type, indicating CsrA indeed affects $y p l A$ expression. The gene encoding $y p l A$ is one of a collection of genes within the hierarchical regulatory cascade of the flagellar T3SS of $Y$. enterocolitica defined as Class III genes [2,13]. Other Class III genes encode proteins essential for maturation of the flagellum, including the filament proteins FleA, FleB and FleC. To determine whether CsrA affected other genes within this class of flagellar genes, expression of fleB was also examined (Figure 3). The $\operatorname{csr} A$ mutant expressed significantly less fle $B$ than wild-type, indicating the effect of CsrA on Class III genes was not limited to $y p l A$. Considering that CsrA affected expression of two different Class III genes, we reasoned that CsrA may act at a higher level within the regulatory cascade. Class III genes are regulated by a sigma factor, FliA, which is encoded by the Class II gene, fliA $[13,14]$. Expression of fliA is, in turn, governed by the master motility regulators, FlhD and FlhC. The FlhDC complex is encoded by Class I genes and is required for expression of all other flagellar genes [15-17]. Therefore, to determine the effect of CsrA on the upstream regulators of $y p l A$ and $f l e B$, expression of $f l i A$ and $f l h D C$ was examined (Figure 3). Expression of $f l i A$ and $f l h D C$ were significantly less in the $\operatorname{csr} A$ mutant relative to wild-type. When $\operatorname{csr} A$ was reintroduced on a low copy plasmid into the $\operatorname{csr} A$ mutant, $\beta$-galactosidase activity was restored at all levels of the flagellar regulatory cascade. These results indicate CsrA affects $y p l A$ expression by activating the upstream regulatory genes

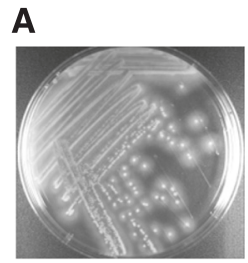

WT

B

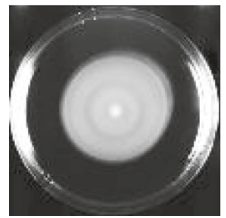

WT

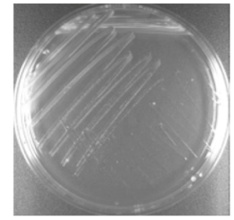

csrA

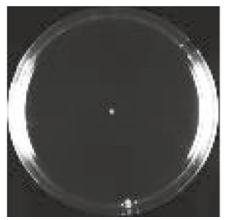

cArs

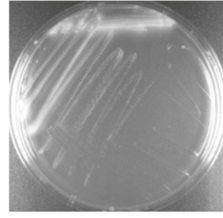

VC

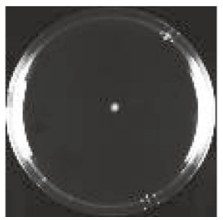

VC

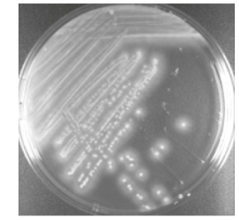

CsrA/csrA+

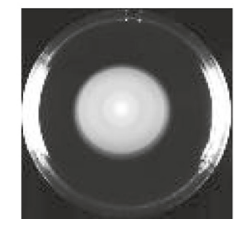

csrA/csrA+

Figure 2 Complementation of GY448 with csrA restores the Yex phenotype and motility. GY123 (WT), GY448 (csrA), GY6536 (VC) and GY6535 ( $c s r A$ csrA+) strains were examined. A) The Yex phenotype was examined by determining phospholipase activity using a modified radial-diffusion assay. Individual colonies were streaked for isolation onto PLA indicator medium. Subsequently, phospholipase activity was detected as a bright white zone of precipitation emanating from isolated colonies. Representative images from three independent experiments. B) Phenotypic assays for motility were initiated by spotting a small portion of a colony at the center of plates containing TYE medium with $0.3 \%$ agar. Subsequently, motility was scored positive if the strains exhibited growth and migration emanating from the point of inoculation. Representative images from three independent experiments. 


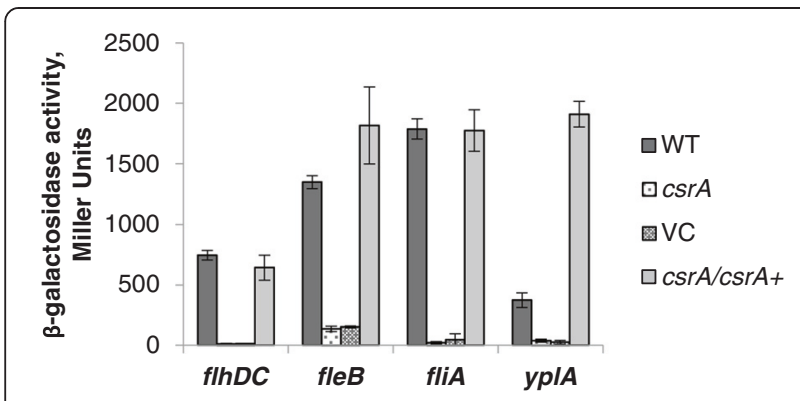

Figure 3 Effect of CsrA on expression of genes within the regulatory hierarchy controlling YpIA export and motility. LacZ production from the vector pFUSE was driven by the upstream region, including the Shine-Dalgarno sequence, of flhDC, fliA, fleB or yplA in strains GY123 (WT), GY448 (csrA), GY6536 (VC) and GY6535 (csrA csr $\mathrm{A}+$ ). Bacterial cells were harvested and assayed for $\beta$-galactosidase activity. Results are averages \pm standard deviation of at least three independent experiments performed in triplicate.

flhDC. Furthermore, these results reveal CsrA affects motility by acting at the top of the regulatory hierarchy that affects flagellar gene expression.

The effect of CsrA on motility has been investigated in numerous bacterial species within the family of Enterobacteriaceae, which includes the Yersiniae. These studies indicate that regulation of motility by CsrA is not conserved. Mutation of csrA in E. coli, Yersinia pseudotuberculosis and $S$. Typhimurium results in loss of flagella [18-21]. In E. coli, it was demonstrated that regulatory control by CsrA occurs by binding to and stabilizing the transcript of the master regulator, flhDC $[19,22]$. This appears to also be true in $S$. Typhimurium since mutation of $\operatorname{cs} r A$ results in decreased levels of $f l h D C$ mRNA [21]. Yet $S$. Typhimurium differs because CsrA appears to additionally modulate motility by affecting expression of hilD, a master regulator of virulence genes including those required for motility, and STM1344, a negative regulator of motility [21,23]. CsrA in $Y$. pseudotuberculosis also directly regulates motility by binding to $f h D C$ transcript [20]; yet control of motility by the Csr system in this bacterium also differs because CsrA additionally acts indirectly through activation of $\operatorname{rov} M$, an activator of motility $[20,24]$. It is possible that the same levels of regulatory control occur in $Y$. enterocolitica since there is a rovM homologue present in the genome. In contrast, CsrA (RsmA) in Erwinia carotovora negatively regulates production of flagella by destabilizing the mRNA transcripts of $f l h D C$ and fliA [25]. Thus, even within the family Enterobacteriaceae, the role of CsrA in coordinating physiology is highly malleable. Further diversity in the effect of CsrA on motility is seen in Helicobacter pylori, where CsrA is also required for motility [26]; however, the defect is not due alterations in the amount of major flagellin proteins or assembled flagellar structures. Instead, CsrA appears to either act at a relatively late stage in the motility regulatory hierarchy or affect the ability to use flagella. The diversity seen in how CsrA affects motility exemplifies how the Csr regulon has been differentially shaped to fit the varied lifestyles of bacteria.

C) Mutation of csrA in Y. enterocolitica results in sensitivity to sodium chloride and other osmolytes.

Among the original observations that distinguished GY448 was that it grew on TYE medium but not on LB. The only difference between these two media is the inclusion of $90 \mathrm{mM}$ sodium chloride in LB. To determine the concentration of sodium chloride that led to growth attenuation of the $\operatorname{csr} A$ mutant, wild-type and $\operatorname{csr} A$ mutant strains were cultivated on TYE agar with added sodium chloride at $0,10,20,40,60,100$ and $200 \mathrm{mM}$ (Figure 4A). The csrA mutant was significantly inhibited in the ability to form colonies compared to wild-type when plated on media containing as little as $10 \mathrm{mM}$ sodium chloride $(\mathrm{p}<0.0001)$. Complementation of $\operatorname{csr} A$ completely restored growth at all concentrations of sodium chloride tested. The cloning vector had no effect on the phenotype of the $\operatorname{csr} A$ mutant. This growth attenuation was due to a bacteriostatic effect. Bacteria cultivated in TYE, collected and resuspended in a medium containing $300 \mathrm{mM}$ sodium chloride were used to determine if the csrA mutant could be recovered on TYE agar. There was no significant difference in the ability of the $\operatorname{csr} A$ mutant and wild-type strains to recover and grow on TYE agar after 30 minutes, one hour, two hours, eight hours or 24 hours of sodium chloride exposure (data not shown). These results indicate that $Y$. enterocolitica with mutation in $\operatorname{csr} A$ is sensitive to even low concentrations sodium chloride and that this effect is bacteriostatic.

While the regulatory mechanisms of the Csr system have been well studied, the environmental signals that this complex system responds to remain somewhat obscure $[6,8,9,27,28]$. It is clear that quorum sensing and environmental $\mathrm{pH}$ are important $[27,29,30]$; however the influence of osmolarity has not been investigated. Therefore, we further probed whether the limitation of growth of the csrA mutant due to sodium chloride might be an effect caused by anionic identity, ionic strength or osmolarity. To distinguish the contribution of the anion, the effect of a monovalent salt, a divalent salt and a non-metabolizable carbohydrate were determined (Figure $4 \mathrm{~B}, \mathrm{C}$ and D). It was observed in each case that the csrA mutant displayed growth attenuation and the severity of the effect was titratable. Treatment with potassium chloride and calcium chloride indicated that significantly fewer csrA mutant colonies formed at $20 \mathrm{mM}(\mathrm{p}<0.0001)$ and $40 \mathrm{mM}(\mathrm{p}<0.0001)$, respectively (Figure $4 \mathrm{~B}$ and $\mathrm{C}$ ). At concentrations of $60 \mathrm{mM}$ for both salts, the $\operatorname{csr} A$ mutant completely lost the ability to form colonies. Treatment with rhamnose did not eliminate 

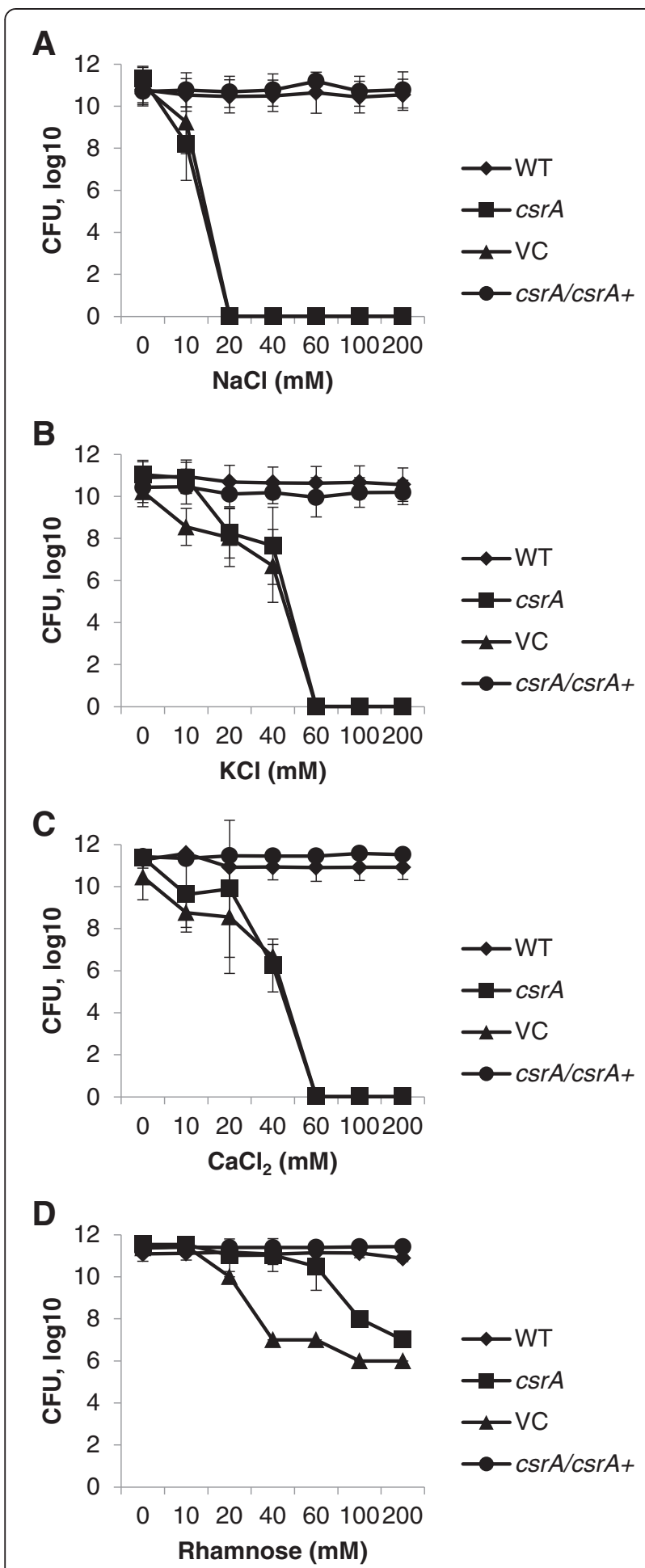

Figure $\mathbf{4}$ Influence of sodium chloride and other osmolytes on colony formation of $Y$. enterocolitica csrA mutant. Strains GY123 (WT), GY448 (csrA), GY6536 (VC) and GY6535 (csrA/csrA+) were cultured and serial dilutions plated onto TYE agar medium with indicated concentrations of A) $\mathrm{NaCl}, \mathbf{B}) \mathrm{KCl}, \mathbf{C}) \mathrm{CaCl}_{2}$ or D) rhamnose. Results represent average number of $\mathrm{CFU} \pm$ standard deviation from at least three independent experiments performed in triplicate. Statistical analysis was performed using repeated measures two-way ANOVA. colony formation of the $\operatorname{csr} A$ mutant at any concentration examined and significantly fewer colonies, relative to wild-type, formed at $100 \mathrm{mM}(\mathrm{p}<0.0001)$ (Figure 4D). Complementation of $\operatorname{csr} A$ on a low-copy plasmid completely restored the ability of the $c s r A$ mutant to form colonies in all cases. These results suggest that high osmolarity is, at least, one element of stress that limits growth.

It is interesting to consider how sensitivity to high ionic strength and high osmolarity may affect the study of $\operatorname{csr} A$ mutant bacteria. Studies in E. coli $\mathrm{K}-12$ are routinely performed on LB medium, using a strain with a transposon insertion located at codon 51, which reportedly retains partial CsrA activity [31,32]. Development of an E. coli K-12 csrA deletion mutant has been attempted but was unsuccessful [32]. This report showed that $\operatorname{csr} A$ was essential for growth on LB medium by demonstrating activation of an inducible plasmid encoding $\operatorname{csr} A$ could restore growth of a $c s r A$ deletion mutant on LB. It was noted that various growth conditions were used while attempting to make the mutant; however it is unclear whether variation in osmolarity was among them. Additionally, $S$. Typhimurium and $Y$. pseudotuberculosis csrA mutants are attenuated for growth on LB medium and Pseudomonas aeruginosa rsmA mutants are restricted for growth when cultured in nutrient yeast broth (NYB) or nutrient broth (NB). All of these media include $90 \mathrm{mM}$ sodium chloride [20,23,33-35]. These reports of varying degrees of growth attenuation, in combination with the findings from this study, make it interesting to consider how CsrA affects bacterial responses to environmental osmolarity in different species. It is possible that CsrA affects both shared and species-specific signaling pathways that coordinate the bacterial response to osmotic cues. The effect of sodium chloride was not explored in the preceding reports; consequently, this study is the first to provide evidence that osmolarity of the growth medium may account for the previously observed phenotypes.

It is also noteworthy to consider how the osmolarity of media may impact experimental outcomes and analysis of the resulting data. For example, $Y$. pseudotuberculosis wild-type and csrA mutant strains were analyzed for expression of the virulence genes rovA and rovM when bacteria were cultured under two different growth conditions [20]. Bacteria were grown in either LB media that included the addition of $90 \mathrm{mM}$ sodium chloride or in minimal media that contained $0.9 \mathrm{mM}$ sodium chloride and $1 \mathrm{mM}$ magnesium sulfate salts. Results of this study indicated that the Csr system affects expression of rovA and rovM in a media-dependent manner. While the media-dependent effect on expression of $c s r A$ itself was modest, the level of $\operatorname{csr} C$ expression was greatly reduced in minimal medium compared to LB medium. This suggests that medium-dependent regulation of virulence 
genes by the Csr system occurs through the control of CsrC levels which may change in response to salt concentration. The results of the current study in $Y$. enterocolitica, in combination with gene expression studies in $Y$. pseudotuberculosis, highlight how understanding the effect of the osmolarity of medium can be an important contributor to interpreting results obtained about the Csr system.

D) Mutation of $\operatorname{csr} A$ in $Y$. enterocolitica results in growth inhibition at $4^{\circ} \mathrm{C}$ and $42^{\circ} \mathrm{C}$.

Growth of many bacterial species is critical to control when it poses a threat to human health or contributes to any of a wide spectrum of economic losses [36]. Food-borne human pathogens and food spoilage microorganisms are most commonly constrained by storing food at low temperatures to minimize health risks, medical costs, food spoilage and recall of produce. Low temperatures affect bacterial growth by compromising membrane functions and reducing DNA replication, transcription and translation [36,37]. Yet some psychrotrophic bacteria are capable of growing despite low temperatures, which allows them to survive the cooling processes used within the food chain. For this reason, it is important to understand how bacteria respond to temperature as an environmental signal. Yersiniae are of particular concern within food systems because they can grow at a wide range of temperatures, from as low as $5^{\circ} \mathrm{C}$ to as high as $42^{\circ} \mathrm{C}$ [38]. To examine whether CsrA affects growth of $Y$. enterocolitica at different temperatures important for food safety, wild-type and $\operatorname{csr} A$ mutant bacteria were grown to stationary phase and plated on TYE. Bacteria were incubated at $6^{\circ} \mathrm{C}, 26^{\circ} \mathrm{C}, 37^{\circ} \mathrm{C}$ and $42^{\circ} \mathrm{C}$ and bacterial growth was quantified (Figure 5). When incubated at $26^{\circ} \mathrm{C}$ or $37^{\circ} \mathrm{C}$, there was no significant difference between the number of colonies formed from cultures of wild-type and $\operatorname{csr} A$ mutant bacteria (Figure $5 \mathrm{~B}$ and $\mathrm{C}$ ). However, at $6^{\circ} \mathrm{C}$ the $\operatorname{csr} A$ mutant was unable to grow (Figure 5A). To determine whether the bacteria remained viable, these plates were subsequently transferred to the more favorable growth temperature of $37^{\circ} \mathrm{C}$. This revealed a three $\log$ reduction in colony forming units (CFU) for the $\operatorname{csr} A$ mutant relative to wild-type (data not shown), indicating incubation at $6^{\circ} \mathrm{C}$ results in some lethality. The ability of bacteria to grow at $42^{\circ} \mathrm{C}$ was also examined. At this temperature, $Y$. enterocolitica does not form individual colonies. However, a threshold at which the collective population would form a lawn on the plate was observed. Using this as the criterion, there was a four log reduction in growth of the $\operatorname{csr} A$ mutant relative to wild-type (Figure 5D). These combined results reveal $\operatorname{csr} A$ is essential for growth of $Y$. enterocolitica at both the low and high ends of the temperature spectrum at which it can grow.

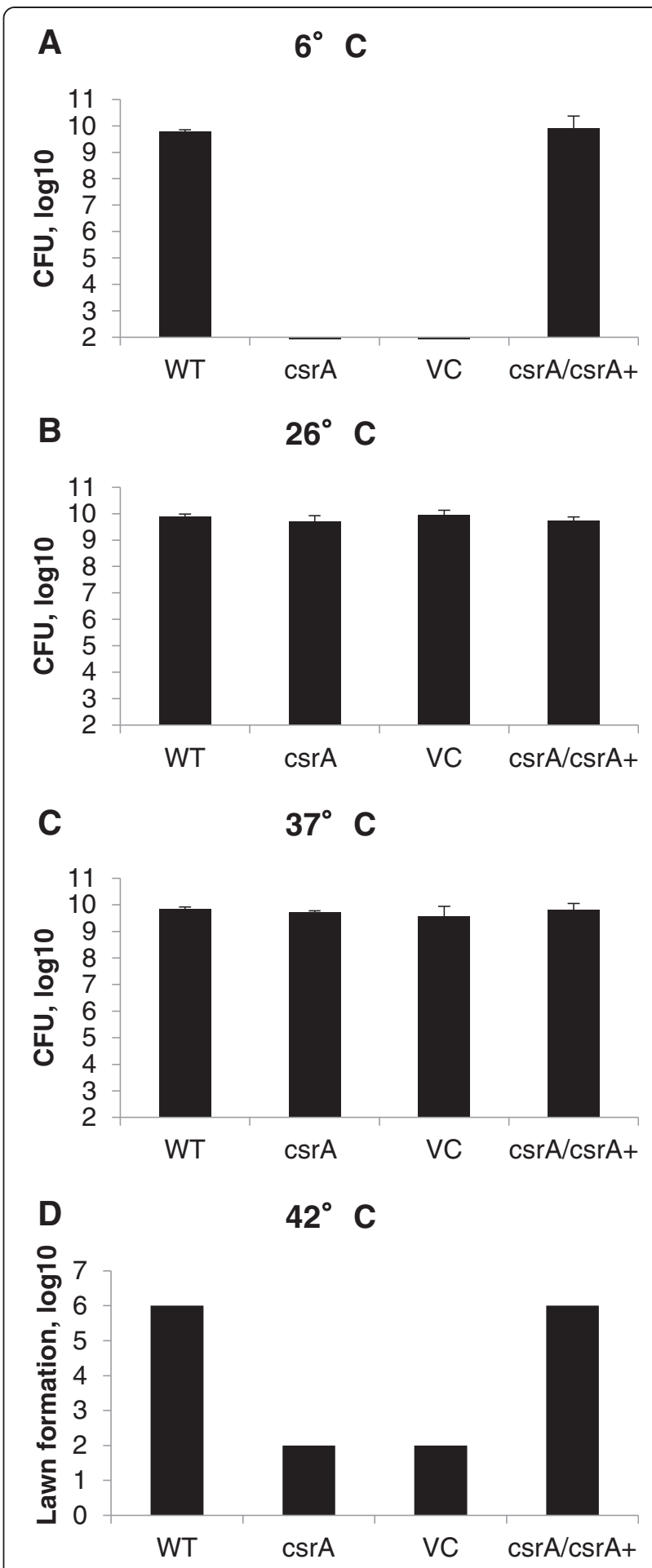

Figure 5 The effect of temperature on growth of the csrA mutant of $Y$. enterocolitica. Strains GY123 (WT), GY448 (csrA), GY6536 (VC) and GY6535 (csrA/csrA+) were cultured and serial dilutions were plated onto TYE agar medium in replicate. One replicate for each strain was incubated at A) $6^{\circ} \mathrm{C}$ for three weeks, B) $26^{\circ} \mathrm{C}$ for 48 hours, C) $37^{\circ} \mathrm{C}$ for 24 hours or $\mathbf{D}) 42^{\circ} \mathrm{C}$ for 24 hours. CFU (A-C) or lawn formation (D) was quantified. Results represent averages \pm standard deviation from three independent experiments performed in triplicate. 
Within scientific literature, it is evident that the Csr system plays an important role in regulating responses of many bacterial species to temperature. A csrA mutant of $S$. Typhimurium was severely impaired for colony formation at $10^{\circ} \mathrm{C}, 15^{\circ} \mathrm{C}$ and $21^{\circ} \mathrm{C}$, but not at $37^{\circ} \mathrm{C}$ [39]. Mutation of $\operatorname{csr} A$ in $H$. pylori had no effect on bacterial viability in response to heat shock; however, in a $\operatorname{csr} A$ mutant, transcription of genes involved in the heat shock response was altered [26]. Also, expression of csr genes themselves are differentially regulated over a broad range of temperatures in $E$. coli and Legionella pneumophila [40,41]. In combination with results of the current study, these reports suggest CsrA may be an important target for investigating temperature-dependent growth of bacterial species, including those that are of significant human health and economic importance.

E) Mutation of $\operatorname{csr} A$ in $Y$. enterocolitica results in increased sensitivity to antibiotics.
Considering the various of physiological changes that are modulated by CsrA, we speculated the $\operatorname{csr} A$ mutant may be altered in ways that affect susceptibility to antibiotics. Therefore, to investigate a broader range of functions that the loss of $\operatorname{csr} A$ may affect, we examined two different classes of antibiotics, a cell wall synthesis inhibitor, ampicillin, and a protein synthesis inhibitor, spectinomycin (Figure 6 and Table 1). The sensitivity of wild-type and $\operatorname{csr} A$ mutant bacteria to these antibiotics was investigated using a disk diffusion assay (Figure 6). The zone of growth inhibition around a disk containing $100 \mathrm{mg} / \mathrm{ml}$ ampicillin or $50 \mathrm{mg} / \mathrm{ml}$ spectinomycin was significantly larger for the $\operatorname{csr} A$ mutant relative to wild-type, indicating mutation of $\operatorname{csr} A$ increased susceptibility of $Y$. enterocolitica to these antibiotics. Another measure of sensitivity to antibiotics, minimum inhibitory concentration (MIC) testing, was also used (Table 1). The MIC of ampicillin was 16-fold greater for wild-type than the $\operatorname{csr} A$ mutant. Furthermore, consistent with results from the disk diffusion assay, the MIC of spectinomycin was at least fourfold

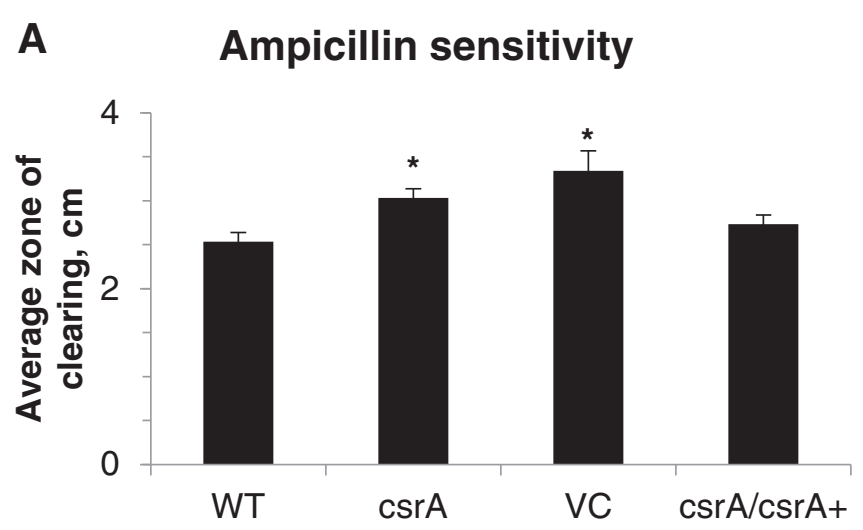

B Spectinomycin sensitivity

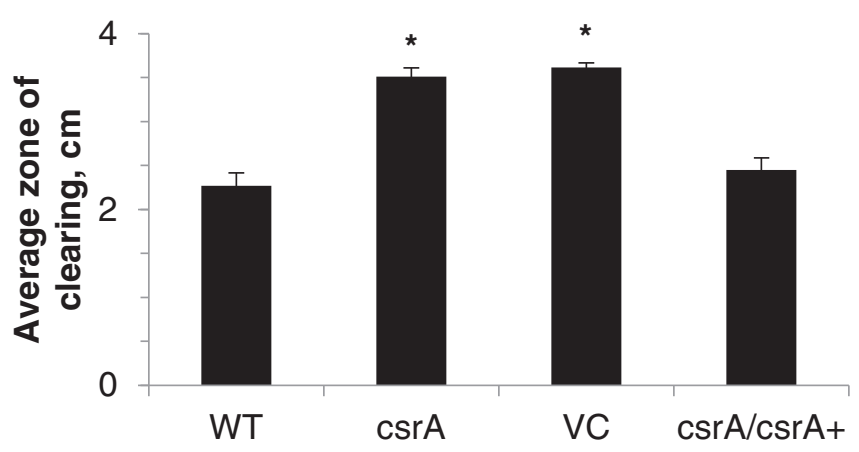

Figure 6 Susceptibility of $Y$. enterocolitica strain JB580v and GY448 to ampicillin and spectinomycin. Strains GY123 (WT), GY448 (cSrA), GY6536 (VC) and GY6535 (csrA/csrA+) were cultured and bacteria were spread onto TYE agar medium. A disk containing A) $100 \mathrm{mg} / \mathrm{ml}$ ampicillin or B) $50 \mathrm{mg} / \mathrm{ml}$ spectinomycin was placed in the center of the plate. After incubation at $26^{\circ} \mathrm{C}$ for 48 hours, the diameter of the zone of growth inhibition around the disk was measured. Results represent averages \pm standard deviation from three independent experiments performed in duplicate. *The p-value compared to WT was $<0.0001$. 
Table 1 Minimum inhibitory concentration ( $\mathrm{mg} / \mathrm{L}$ ) of ampicillin and spectinomycin for $Y$. enterocolitica strain JB580v and GY448

\begin{tabular}{lll}
\hline Strain & Ampicillin & Spectinomycin \\
\hline WT & 400 & 25 \\
CSrA & 25 & $<6.25$ \\
VC & 25 & $<6.25$ \\
CSrA $C S r A+$ & 200 & 25
\end{tabular}

Strains GY123 (WT), GY448 (csrA), GY6536 (VC) and GY6535 (csrA/csrA+) were grown to 0.5 McFarland standard in TYE and inoculated into TYE broth containing concentrations of ampicillin or spectinomycin diluted 1:2 and ranging from 400 $\mathrm{mg} / \mathrm{ml}$ to $6.25 \mathrm{mg} / \mathrm{ml}$. MIC was determined based on visible growth in samples after incubation for 36 hours at $26^{\circ} \mathrm{C}$. Results from three independent experiments performed in duplicate.

greater for wild-type than the $\operatorname{csr} A$ mutant, since the $\operatorname{csr} A$ mutant was inhibited by the lowest concentration of spectinomycin examined. These experimental outcomes indicate mutation of $\operatorname{csr} A$ in $Y$. enterocolitica results in increased susceptibility to two antibiotics with different mechanisms of action. It is not apparent from studies of CsrA in other bacterial species whether increased sensitivity to antibiotics has been observed in $\operatorname{csr} A$ mutant bacteria. This is the first report, to our knowledge, to indicate a role for CsrA in modulating bacterial responses to antibiotics. It is particularly noteworthy that CsrA controls physiological responses to antibiotics with different mechanisms of action. This finding, in combination with other results from this study, indicates CsrA is involved in controlling multiple regulatory cascades that coordinate bacterial responses to a wide variety of environmental cues.

\section{Conclusions}

This study compiled evidence that CsrA has the ability to function differently in closely related species of bacteria and showed it modulates a diverse array of physiological processes in $Y$. enterocolitica. These findings may reflect bacterial lifestyle characteristics. $Y$. enterocolitica has an unusual ability to grow at low temperatures that occur during its free-living stages in terrestrial environments which are interrupted by episodes of parasitic growth as a pathogen in mammalian hosts. Also based on the results of this study, it is interesting to consider how alterations in temperature, osmolarity and antibiotic concentrations may be useful tools on a practical level. It is possible that modification of growth conditions may aid development of $\operatorname{csr} A$ mutant strains and help circumvent issues related to growth attenuation of $\operatorname{csr} A$ mutants.

\section{Methods}

\section{Bacterial strains and media}

The bacterial strains used in this study are described in Table 2. Strains of Escherichia coli were routinely grown at $37^{\circ} \mathrm{C}$ in Luria-Bertani (LB) broth ( $1 \%$ tryptone, $0.5 \%$ yeast extract, and $90 \mathrm{mM} \mathrm{NaCl}$ ) or on LB agarose (Difco, Detroit, MI). Yersinia enterocolitica strains were grown at $26^{\circ} \mathrm{C}$ in Tryptone-Yeast Extract (TYE) broth (1\% tryptone, $0.5 \%$ yeast extract) or on TYE agarose (Difco, Detroit, MI). Semisolid medium for the examination of motility contained $0.3 \%$ Difco agar. Phospholipase indicator agar (PLA) consisted of TYE medium supplemented with 1\% Tween 80 and $1 \mathrm{mM} \mathrm{CaCl}_{2}$ [4] and solidified with $2 \%$ (wt/

Table 2 Bacterial strains and plasmids used in this study

\begin{tabular}{|c|c|c|}
\hline $\begin{array}{l}\text { Bacterial strain } \\
\text { or plasmid }\end{array}$ & $\begin{array}{l}\text { Genotype or relevant } \\
\text { characteristics }\end{array}$ & $\begin{array}{l}\text { Source ol } \\
\text { reference }\end{array}$ \\
\hline \multicolumn{3}{|c|}{ Y. enterocolitica strains } \\
\hline JB580V & Serogroup O:8, $\mathrm{Nal}^{r}$ syen $R\left(\mathrm{R}^{-}, \mathrm{M}^{+}\right)$ & [42] \\
\hline GY448 & csrA::TnMod-RKm' & [3] \\
\hline GY6536 & csrA::TnMod-RKm' pTM100 & This study \\
\hline GY6535 & csrA::TnMod-RKm' csrA::pTM100 & This study \\
\hline GY6575 & cSrA::TnMod-RKm' flhDC:::pFUSE & This study \\
\hline GY6576 & csrA::TnMod-RKm' fleB::pFUSE & This study \\
\hline GY6577 & csrA::TnMod-RKm' fliA::.pFUSE & This study \\
\hline GY6578 & csrA::TnMod-RKm' yp/A::pFUSE & This study \\
\hline GY6579 & $\begin{array}{l}\text { csrA::TnMod-RKm' csrA::pTM100 flhDC:: } \\
\text { pFUSE }\end{array}$ & This study \\
\hline GY6581 & $\begin{array}{l}\text { csrA::TnMod-RKm' csrA::pTM100 fleB:: } \\
\text { pFUSE }\end{array}$ & This study \\
\hline GY6582 & $\begin{array}{l}\text { csrA::TnMod-RKm' csrA::pTM100 fliA:: } \\
\text { pFUSE }\end{array}$ & This study \\
\hline GY6583 & $\begin{array}{l}\text { csrA::TnMod-RKm' csrA::pTM100 yp/A:: } \\
\text { pFUSE }\end{array}$ & This study \\
\hline GY6584 & csrA::TnMod-RKm' pTM100 flhDC:::pFUSE & This study \\
\hline GY6585 & csrA::TnMod-RKm' pTM100 fleB::pFUSE & This study \\
\hline GY6586 & csrA::TnMod-RKm' pTM100 fliA::pFUSE & This study \\
\hline GY6587 & csrA::TnMod-RKm' pTM100 yplA::pFUSE & This study \\
\hline \multicolumn{3}{|l|}{ E. coli strains } \\
\hline $\mathrm{DH} 5 \mathrm{a}$ & $\begin{array}{l}\mathrm{F}^{-} \text {p80lacZDM15 } \triangle(\text { lacZYA-argF)U169 } \\
\text { recA1 endA1 hsdR17( }\left(_{-}^{-}, \mathrm{m}_{k}^{+}\right) \text {phoA supE44 } \\
\text { thi-1 gyrA96 relA1 } \lambda^{-}\end{array}$ & [43] \\
\hline S17-1 $\lambda$ pir & 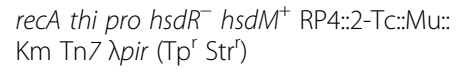 & [44] \\
\hline \multicolumn{3}{|l|}{ Plasmids } \\
\hline $\begin{array}{l}\text { pCR-Blunt II- } \\
\text { TOPO }\end{array}$ & $\mathrm{Km}^{\mathrm{r}}$ & Invitrogen \\
\hline pFUSE & $\begin{array}{l}\mathrm{Cm}^{r} \text {, mob }{ }^{+} \text {, oriR6K, suicide vector for } \\
\text { transcriptional fusions to lacZYA }\end{array}$ & [45] \\
\hline pTM100 & $\mathrm{mob}^{+}$, derivative of pACYC184, $\mathrm{Cm}^{r}$ Tet $^{r}$ & [46] \\
\hline pGY1298 & $\begin{array}{l}\text { pTM100 with a } 0.5-\mathrm{kb} \text { fragment } \\
\text { containing csrA not directional to cat } \\
\text { promoter }\end{array}$ & This study \\
\hline pGY714 & pFUSE with flhDC promoter fragment & [47] \\
\hline pGY716 & pFUSE with fleB promoter fragment & {$[47]$} \\
\hline pGY715 & pFUSE with fliA promoter fragment & [47] \\
\hline pGY713 & pFUSE with yp/A promoter fragment & [2] \\
\hline
\end{tabular}


vol) agarose (Difco, Detroit, MI). Antibiotics (in micrograms per milliliter) were used as follows. For Y. enterocolitica, working concentrations were chloramphenicol, 10; kanamycin, 50; nalidixic acid, 20 and tetracycline, 7.5. For E. coli, working concentrations were chloramphenicol, 25; kanamycin, 50 and tetracycline, 15.

\section{Characterization of transposon insertions sites and DNA sequencing}

Chromosomal DNA was isolated from mutants that contained TnMod-RKm' insertions and was digested with EcoRI. The digested DNA was ligated overnight, and replicating plasmids were recovered by electroporation of E. coli S17-1 גpir followed by selection for kanamycin resistance [48]. Direct cloning of the transposon/ chromosome junction was facilitated by the presence of a conditional oriR6K in TnMod-RKm' that can function in specialized E. coli strains that carry a copy of pir [44]. Plasmids were isolated and analyzed by restriction digest to confirm the integrity of the transposon sequences. The sequence of the chromosomal DNA immediately adjacent to the transposon was then determined using primers that annealed near the ends of TnMod-RKm' (primer KM1, 5' - CCCCGAGCTCTTAATTAA - 3', and primer KM2, 5' - GAACACTTAACGGCTGAC $\left.3^{\prime}\right)$. DNA sequence was obtained using an ABI Prism ${ }^{\circ}$ 3730 Genetic Analyzer and BigDye Terminator v. 3.1 Cycle Sequencing Kit with Gel Company Better Buffer (Applied Biosystems Inc., Foster City, CA).

\section{Construction of plasmids and bacterial strains}

General DNA manipulations were done as described previously [49]. PCR-based DNA amplification of the chromosomal region containing csrA from wild-type $Y$. enterocolitica JB580v was performed using PfuTurbo DNA polymerase (Stratagene, La Jolla, CA). PCR used upstream primer $\operatorname{csrA1}\left(5^{\prime}\right.$ - CAATGCGCCATATCTCTATG - 3') and downstream primer csrA3 (5' - GTAACACGAGACGCTTCTTC - 3'), resulting in a 442 basepair fragment of the region of the $Y$. enterocolitica chromosome from -232 to +210 relative to the translational start site of $c s r A$. The DNA fragment was gel purified using a QIAquick gel extraction kit (Qiagen). The purified PCR product was initially cloned into pCR-Blunt II-TOPO (pTOPO) according to the manufacturer's instructions (Invitrogen, Grand Island, NY). Plasmid DNA was isolated from E. coli DH5 $\alpha$ using a QIAprep spin miniprep kit (Qiagen, Valencia, CA). The DNA fragment was then released by digestion with EcoRI (New England Biolabs, Ipswich, MA) for ligation into the same sites of the plasmid-based expression vector pTM100 [46] using T4 DNA ligase (New England Biolabs, Ipswich, MA). The nucleotide sequence of DNA generated by PCR was determined to confirm that there were no point mutations.
DNA sequencing was performed at the DNA sequencing facility of University of California, Davis on an ABI Prism 3730 Genetic Analyzer using BigDye Terminator v. 3.1 Cycle Sequencing Kit with Gel Company Better Buffer (Applied Biosystems Inc., Foster City, CA). The direction of csrA to the promoter of the chloramphenicol acetyltransferase (cat) gene was investigated by PCR using vector primer $p$ TM1002HA1 (5' - GGATCCCTATCCCATA TCACCAGCTC - 3') and insert primer $\operatorname{csr} A 1\left(5^{\prime}\right.$ - CAA TGCGCCATATCTCTATG - $3^{\prime}$ ) or vector primer pTM1002HA3 (5' - GTCGACCTATAACCAGACCGTT CAGC $\left.-3^{\prime}\right)$ and insert primer $\operatorname{csr} 33\left(5^{\prime}\right.$ - GTAACAC GAGACGCTTCTTC $-3^{\prime}$ ). The resulting pTM100 plasmid with $c s r A$ oriented in the opposite direction of the cat

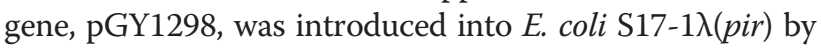
electroporation then mobilized into $Y$. enterocolitica strain GY448 by conjugation [50-52]. Previously constructed pFUSE plasmids were similarly mobilized from E. coli S17-1 $\lambda$ (pir) into the indicated strains of $Y$. enterocolitica by conjugation.

\section{Phospholipase assays}

Phospholipase activity in a sample was determined by a modified radial-diffusion assay [53]. Individual colonies were streaked for isolation onto TYE plates containing $1 \%$ Tween 80 and $1 \mathrm{mM} \mathrm{CaCl}_{2}$ (PLA medium) [1,4]. Plates were imaged after incubation at $26^{\circ} \mathrm{C}$ for $48 \mathrm{hr}$. Phospholipase activity was detected as a zone of precipitation emanating from isolated colonies. Plates were imaged on a BioSpectrum Multispectral Imaging System (UVP, Upland, CA).

\section{Assays for motility}

Phenotypic assays for motility were initiated by spotting a small portion of a colony at the center of fresh TYE plates containing $0.3 \%$ agar, as described previously [17]. After 48 hours incubation at $26^{\circ} \mathrm{C}$, plates were imaged on a BioSpectrum Multispectral Imaging System (UVP, Upland, CA). Motility was scored as positive if the strains exhibited growth and migration emanating from the point of inoculation.

\section{Measurements of $\beta$-galactosidase activity}

$Y$. enterocolitica harboring lacZYA ranscriptional fusions were cultured overnight at $26^{\circ} \mathrm{C}$ in TYE medium and subcultured to an $\mathrm{OD}_{600}$ of 0.1 in $5 \mathrm{ml}$ TYE. Cultures were incubated at $26^{\circ} \mathrm{C}$ for 6 hours. Bacterial cells were harvested then assayed for $\beta$-galactosidase activity as previously described [54].

\section{Osmolyte and temperature sensitivity assays}

$Y$. enterocolitica was grown in TYE medium at $26^{\circ} \mathrm{C}$ overnight. Serial dilutions were plated in triplicate onto plates containing TYE medium. For osmolyte assays, 
plates with added $\mathrm{NaCl}, \mathrm{KCl}, \mathrm{CaCl}_{2}$ or rhamnose at final concentrations of $10 \mathrm{mM}, 20 \mathrm{mM}, 40 \mathrm{mM}, 60 \mathrm{mM}$, $100 \mathrm{mM}$ and $200 \mathrm{mM}$ were also used. Plates were incubated at $26^{\circ} \mathrm{C}$ for 48 hours except where noted for temperature sensitivity assays, in which case replicate plates were also incubated at $6^{\circ} \mathrm{C}$ for three weeks, $37^{\circ} \mathrm{C}$ for 24 hours and $42^{\circ} \mathrm{C}$ for 24 hours. Subsequently, colony forming units were quantified, with the exception of plates incubated at $42^{\circ} \mathrm{C}$. At this temperature, bacteria were unable to form individual colonies at any dilution. Bacteria either exhibited no growth or growth in the form of a lawn. Therefore, bacterial growth was reported as the dilution at which a lawn was present (threshold lawn formation).

\section{Antibiotic susceptibility assays}

$Y$. enterocolitica was grown in TYE medium at $26^{\circ} \mathrm{C}$ overnight. Sterile cotton swabs were used to distribute bacteria evenly across the surface of TYE agar medium. A disk containing either $100 \mathrm{mg} / \mathrm{ml}$ ampicillin or $50 \mathrm{mg} / \mathrm{ml}$ spectinomycin was placed in the center of the plate and incubated at $26^{\circ} \mathrm{C}$ for 48 hours. The diameter of the zone of clearing around the disk was measured in centimeters. Determination of minimum inhibitory concentration (MIC) of ampicillin and spectinomycin was also performed as previously described [55]. Briefly, indicated strains were grown to $0.5 \mathrm{McFarland}$ standard and inoculated into TYE broth containing 1:2 dilutions of ampicillin or spectinomycin. MIC was determined based on visible growth after incubation for 36 hours at $26^{\circ} \mathrm{C}$.

\section{Statistical analysis}

Data were analyzed using one-way between subjects analysis of variance and Tukey's post hoc test, except where indicated, to determine statistically significant $\mathrm{p}$-values at $\mathrm{p}<0.05$.

\section{Abbreviations \\ CFU: Colony forming units; CsrA: Carbon storage regulator A; LB: Lauria-Bertani; orf. Open reading frame; MIC: Minimum inhibitory concentration; T3SS: Type three secretion system; TYE: Tryptone yeast extract; VC: Vector control plasmid pTM100; WT: Wild-type; Yex: YplA export phenotype.}

\section{Competing interests}

The authors declare that they have no competing interests.

\footnotetext{
Authors' contributions

$\mathrm{KL}$ participated in bioinformatic analysis and all experiments, carried out antibiotic and temperature sensitivity experiments, performed statistical analysis, coordinated the study and drafted the manuscript. SP developed the transposon library, participated in bioinformatic analysis and identified the mutant used in this study. YZ carried out the osmolyte sensitivity experiments, performed statistical analysis and participated in gene expression experiments, data interpretation and critical review of the manuscript. KKL participated in bioinformatic analysis, participated in sodium chloride sensitivity experiments, and performed genetic complementation experiments. GO participated in sodium chloride sensitivity experiments and gene expression experiments. JYC participated in genetic complementation experiments. GMY conceived the study, participated in data interpretation, participated in coordination
}

of the study, and performed critical revisions of the manuscript. All authors read and approved the final manuscript.

\section{Acknowledgements}

This work was supported in part by a grant from the National Institutes of Health (NIH), R21 Al156042 to GMY, the Henry A. Jastro Graduate Research Award to KL and the Henry A. Jastro Graduate Research Award to GO. $\mathrm{KL}$ was supported by the National Science Foundation Graduate Research Fellowship Program Grant DGE-1148897, the NIH Animal Models of Infectious Disease Training Grant T32 Al060555 and the NIH Initiative for Maximizing Student Diversity Education Grant R25 GM056765. GO was supported by the Turkish Ministry of National Education. YZ and JYC were supported by The China Scholarship Council. These authors declare no conflicts of interest, nor any competing financial interests.

\section{Author details}

${ }^{1}$ Microbiology Graduate Group, University of California, Davis, CA, USA. ${ }^{2}$ Department of Food Science and Technology, University of California, Davis, Davis, CA, USA. ${ }^{3}$ College of Food Science, Shenyang Agricultural University, Shenyang, PR China. ${ }^{4}$ College of Food Science and Nutritional Engineering, China Agricultural University, Beijing, China.

Received: 1 October 2014 Accepted: 13 January 2015

Published online: 14 February 2015

\section{References}

1. Young BM, Young GM. YplA is exported by the Ysc, Ysa, and flagellar type III secretion systems of Yersinia enterocolitica. J Bacteriol. 2002;184:1324-34.

2. Schmiel DH, Young GM, Miller VL. The Yersinia enterocolitica phospholipase gene yp/A is part of the flagellar regulon. J Bacteriol. 2000;182:2314-20.

3. Petersen S, Young GM. Essential role for cyclic AMP and its receptor protein in Yersinia enterocolitica virulence. Infect Immun. 2002;70:3665-72.

4. Young GM, Schmiel DH, Miller VL. A new pathway for the secretion of virulence factors by bacteria: the flagellar export apparatus functions as a protein-secretion system. Proc Natl Acad Sci. 1999;96:6456-61.

5. Romeo T, Vakulskas CA, Babitzke P. Post-transcriptional regulation on a global scale: form and function of Csr/Rsm systems. Environ Microbiol. 2012;15:313-24.

6. Romeo T. Global regulation by the small RNA-binding protein CsrA and the non-coding RNA molecule CsrB. Mol Microbiol. 1998;29:1321-30.

7. Liu MY, Gui G, Wei B, Preston JF, Oakford L, Yüksel Ü, et al. The RNA molecule CsrB binds to the global regulatory protein CsrA and antagonizes its activity in Escherichia coli. J Biol Chem. 1997;272:17502-10.

8. Weilbacher T, Suzuki K, Dubey AK, Wang X, Gudapaty S, Morozov I, et al. A novel sRNA component of the carbon storage regulatory system of Escherichia coli. Mol Microbiol. 2003:48:657-70.

9. Suzuki K, Babitzke P, Kushner SR, Romeo T. Identification of a novel regulatory protein $(\mathrm{CsrD})$ that targets the global regulatory RNAs $\mathrm{CsrB}$ and CsrC for degradation by RNase E. Genes Dev. 2006;20:2605-17.

10. Mercante J, Suzuki K, Cheng X, Babitzke P, Romeo T. Comprehensive Alaninescanning Mutagenesis of Escherichia coli CsrA Defines Two Subdomains of Critical Functional Importance. J Biol Chem. 2006;281:31832-42.

11. Gutiérrez P, Li Y, Osborne MJ, Pomerantseva E, Liu Q, Gehring K. Solution structure of the carbon storage regulator protein CsrA from Escherichia coli. J Bacteriol. 2005;187:3496-501.

12. Heeb S, Kuehne SA, Bycroft M, Crivii S, Allen MD, Haas D, et al. Functional analysis of the post-transcriptional regulator RsmA reveals a novel RNA-binding site. J Mol Biol. 2006;355:1026-36.

13. Kapatral V, Olson JW, Pepe JC, Miller VL, Minnich SA. Temperature-dependent regulation of Yersinia enterocolitica Class III flagellar genes. Mol Microbiol. 1996:19:1061-71

14. Iriarte M, Stainier I, Mikulskis AV, Cornelis GR. The fliA gene encoding sigma 28 in Yersinia enterocolitica. J Bacteriol. 1995;177:2299-304.

15. Bartlett DH, Frantz BB, Matsumura P. Flagellar transcriptional activators FlbB and Flal: gene sequences and 5 ' consensus sequences of operons under FlbB and Flal control. J Bacteriol. 1988;170:1575-81.

16. Liu X, Matsumura P. The FlhD/FlhC complex, a transcriptional activator of the Escherichia coli flagellar class II operons. J Bacteriol. 1994;176:7345-51. 
17. Young GM, Smith MJ, Minnich SA, Miller VL. The Yersinia enterocolitica motility master regulatory operon, flhDC, is required for flagellin production, swimming motility, and swarming motility. J Bacteriol. 1999;181:2823-33.

18. Lawhon SD, Frye JG, Suyemoto M, Porwollik S, McClelland M, Altier C. Global regulation by CsrA in Salmonella Typhimurium. Mol Microbiol. 2003;48:1633-45.

19. Wei BL, Brun-Zinkernagel AM, Simecka JW, Prüß BM, Babitzke P, Romeo T. Positive regulation of motility and flhDC expression by the RNA-binding protein CsrA of Escherichia coli. Mol Microbiol. 2001;40:245-56.

20. Heroven AK, Böhme K, Rohde M, Dersch P. A Csr-type regulatory system, including small non-coding RNAs, regulates the global virulence regulator RovA of Yersinia pseudotuberculosis through RovM. Mol Microbiol. 2008:68:1179-95.

21. Jonas K, Edwards AN, Ahmad I, Romeo T, Römling U, Melefors Ö. Complex regulatory network encompassing the Csr, c-di-GMP and motility systems of Salmonella Typhimurium. Environ Microbiol. 2010;12:524-40.

22. Yakhnin AV, Baker CS, Vakulskas CA, Yakhnin H, Berezin I, Romeo T, et al. CsrA activates flhDC expression by protecting flhDC mRNA from RNase E-mediated cleavage. Mol Microbiol. 2013;87:851-66.

23. Martínez LC, Yakhnin H, Camacho Ml, Georgellis D, Babitzke P, Puente JL, et al. Integration of a complex regulatory cascade involving the SirA/BarA and Csr global regulatory systems that controls expression of the Salmonella SPI-1 and SPI-2 virulence regulons through HilD. Mol Microbiol. 2011;80:1637-56

24. Heroven AK, Dersch P. RovM, a novel LysR-type regulator of the virulence activator gene rovA, controls cell invasion, virulence and motility of Yersinia pseudotuberculosis. Mol Microbiol. 2006:62:1469-83.

25. Chatterjee A, Cui Y, Chakrabarty P, Chatterjee AK. Regulation of motility in Erwinia carotovora subsp. carotovora: quorum-sensing signal controls FlhDC, the global regulator of flagellar and exoprotein genes, by modulating the production of RsmA, an RNA-binding protein. Mol Plant Microbe Interact. 2010;23:1316-23.

26. Barnard FM, Loughlin MF, Fainberg HP, Messenger MP, Ussery DW, Williams $P$, et al. Global regulation of virulence and the stress response by CsrA in the highly adapted human gastric pathogen Helicobacter pylori. Mol Microbiol. 2004:51:15-32

27. Suzuki K, Wang X, Weilbacher T, Pernestig AK, Melefors Ö, Georgellis D, et al. Regulatory circuitry of the CsrA/CsrB and BarA/UvrY systems of Escherichia coli. J Bacteriol. 2002;184:5130-40.

28. Romeo T (Ed). Bacterial biofilms. In: Current topics in microbiology and immunology. 2008, 322. 1-293.

29. Babitzke P, Romeo T. CsrB sRNA family: sequestration of RNA-binding regulatory proteins. Curr Opin Microbiol. 2007;10:156-63.

30. Mondragón V, Franco B, Jonas K, Suzuki K, Romeo T, Melefors Ö, et al. pH-dependent activation of the BarA-UvrY two-component system in Escherichia coli. J Bacteriol. 2006;188:8303-6.

31. Romeo T, Gong M, Liu MY, Brun-Zinkernagel AM. Identification and molecular characterization of CSrA, a pleiotropic gene from Escherichia coli that affects glycogen biosynthesis, gluconeogenesis, cell size, and surface properties. J Bacteriol. 1993;175:4744-55.

32. Timmermans J, Van Melderen L. Conditional essentiality of the csrA Gene in Escherichia coli. J Bacteriol. 2009;191:1722-4.

33. Altier C, Suyemoto M, Lawhon SD. Regulation of Salmonella enterica Serovar Typhimurium invasion genes by csrA. Infect Immun. 2000;68:6790-7.

34. Pessi G, Williams F, Hindle Z, Heurlier K, Holden MTG, Cámara M, et al. The global posttranscriptional regulator RsmA modulates production of virulence determinants and N-Acylhomoserine lactones in Pseudomonas aeruginosa. J Bacteriol. 2001;183:6676-83.

35. Stanisich VA, Holloway BW. A mutant sex factor of Pseudomonas aeruginosa. Genet Res. 1972;19:91-108.

36. Jay JM, Loessner MJ, Golden DA. Protection of foods with low-temperatures, and characteristics of psychrotrophic microorganisms. In: Modern food microbiology, food science text series. 7th ed. New York: Springer; 2005. p. 395-413.

37. Wouters JA, Rombouts FM, Kuipers OP, de Vos WM, Abee T. The role of cold-shock proteins in low-temperature adaptation of food-related bacteria. Syst Appl Microbiol. 2000;23:165-73.

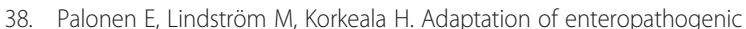
Yersinia to low growth temperature. Crit Rev Microbiol. 2010;36:54-67.
39. Knudsen GM, Nielsen MB, Thomsen LE, Aabo S, Rychlik I, Olsen JE. The role of ClpP; RpoS and CsrA in growth and filament formation of Salmonella enterica serovar Typhimurium at low temperature. BMC Microbiol. 2014;14:208

40. Vakulskas CA, Pannuri A, Cortés-Selva D, Zere TR, Ahmer BM, Babitzke P, et al. Global effects of the DEAD-box RNA helicase DeaD (CsdA) on gene expression over a broad range of temperatures. Mol Microbiol. 2014;92:945-58

41. Ohno A, Kato N, Sakamoto R, Kimura S, Yamaguchi K. Temperature-dependent parasitic relationship between Legionella pneumophila and a free-living amoeba (Acanthamoeba castellanii). Appl Environ Microbiol. 2008;74:4585-8.

42. Kinder SA, Badger JL, Bryant GO, Pepe JC, Miller VL. Cloning of the Yenl restriction endonuclease and methyltransferase from Yersinia enterocolitica serotype $\mathrm{O} 8$ and construction of a transformable R-M+ mutant. Gene. 1993;136:271-5.

43. Maniatis T, Fritsch EF, Sambrook J. Molecular cloning: a laboratory manual. Cold Spring Harbor, NY: Cold Spring Harbor Laboratory Press; 1982.

44. Simon R, Priefer U, Puhler A. A broad host range mobilization system for in vivo genetic engineering: transposon mutagenesis in gram negative bacteria. Bio/Technol. 1983;1:784-91.

45. Bäumler AJ, Tsolis RM, Van der Velden AWM, Stojiljkovic I, Anic S, Heffron F. Identification of a new iron regulated locus of Salmonella typhi. Gene. 1996;183:207-13

46. Michiels T, Cornelis GR. Secretion of hybrid proteins by the Yersinia Yop export system. J Bacteriol. 1991;173:1677-85

47. Venecia K, Young GM. Environmental regulation and virulence attributes of the Ysa type III secretion system of Yersinia enterocolitica Biovar 1B. Infect Immun. 2005;73:5961-77.

48. Dennis JJ, Zylstra GJ. Plasposons: modular self-cloning minitransposon derivatives for rapid genetic analysis of gram-negative bacterial genomes. Appl Environ Microbiol. 1998;64:2710-5.

49. Ausubel FM, Brent R, Kingston RE, Moore DD, Seidman JG, Smith JA, et al. Current protocols in molecular biology. New York: John Wiley \& Sons; 2001

50. Figurski DH, Helinski DR. Replication of an origin-containing derivative of plasmid RK2 dependent on a plasmid function provided in trans. Proc Natl Acad Sci. 1979;76:1648-52.

51. Herrero $M$, de Lorenzo $V$, Timmis KN. Transposon vectors containing non-antibiotic resistance selection markers for cloning and stable chromosomal insertion of foreign genes in gram-negative bacteria. J Bacteriol. 1990;172:6557-67.

52. Young GM, Miller VL. Identification of novel chromosomal loci affecting Yersinia enterocolitica pathogenesis. Mol Microbiol. 1997;25:319-28.

53. Givskov M, Olsen L, Molin S. Cloning and expression in Escherichia coli of the gene for extracellular phospholipase A1 from Serratia liquefaciens. J Bacteriol. 1988;170:5855-62.

54. Miller JH. Experiments in molecular genetics. Cold Spring Harbor, NY: Cold Spring Harbor Laboratory Press; 1972.

55. Andrews JM. Determination of minimum inhibitory concentrations. J Antimicrob Chemother. 2001;48:5-16.

\section{Submit your next manuscript to BioMed Central and take full advantage of:}

- Convenient online submission

- Thorough peer review

- No space constraints or color figure charges

- Immediate publication on acceptance

- Inclusion in PubMed, CAS, Scopus and Google Scholar

- Research which is freely available for redistribution 